\title{
A LITERATURA EM PRODUÇÕES AUDIOVISUAIS: UMA REFLEXÃO SOBRE A DIFERENÇA
}

\author{
Francisco Wellington Borges Gomes
}

\section{Introdução}

O surgimento de novos artefatos tecnológicos sempre provocou efeitos na produção e divulgação de textos literários. Da epopeia de Gilgamesh em tábuas de argila do século VII a. C., passando pela invenção da prensa por tipos móveis no século $\mathrm{XV}$, indo até o surgimento das narrativas visuais no cinema, na televisão e na internet, no século $\mathrm{XX}$, temos visto profundas modificações no modo de produzir e de consumir textos literários.

O cinema, por exemplo, oficialmente criado em 1895 pelos irmãos Lumière, sempre esteve intimamente ligado à literatura. Em 1902, por exemplo, George Méliès, um dos pioneiros da sétima arte, recorreu à obra de Júlio Verne Da Terra à Lua para buscar inspiração para o seu filme Viagem à Lua. Assim como Méliès, incontáveis outros cineastas têm buscado inspiração na literatura para a construção de narrativas visuais. Essa conexão entre literatura e produções audiovisuais recebe nomes variados como tradução, adaptação, transcriação, transposição, dentre outros, que refletem graus variados de intimidade e fidelidade entre o texto audiovisual traduzido e o texto escrito original, assim como ideologias sobre o conceito e o papel do texto literário e suas relações com as mídias audiovisuais.

De modo análogo ao cinema, a TV, criada na década de 1920 e popularizada no Brasil a partir da década de 1950 com a importação de 200 aparelhos por Assis Chateaubriand, mantém uma relação muito próxima com a literatura. De acordo com Guimarães:

\footnotetext{
A recorrência à literatura, portanto, atravessa a história da TV brasileira em adaptações de textos literários realizadas por diversos tipos de programa. De 1952 a 1994, foram 223 novelas adaptadas de textos literários, o que corresponde a mais de um terço de todas as telenovelas produzidas nesse período. (Guimarães, 1996, p. 192)
}

Dentre as discussões sobre a relação entre tradução e literatura estão aquelas relativas ao status do texto traduzido em relação à obra original, assim como o papel do tradutor na construção do texto traduzido. A partir de tais discussões, alguns questionamentos se destacam: Seria o texto traduzido inferior ao texto original e o 
tradutor apenas o responsável pela transferência dos sentidos do texto original na obra traduzida, eximindo-se de qualquer autoria? Ou seria o texto traduzido um novo texto, resultado do trabalho criativo do tradutor?

Tais perguntas refletem posicionamentos divergentes sobre o conceito de literatura e o papel do texto literário nas mídias. De um lado, temos alegações de que as traduções de obras literárias, incluindo-se aquelas para os meios audiovisuais, proporcionariam somente um contato superficial com a obra literária e que as traduções, com grande frequência, fugiriam à fidelidade ao texto original. De outro lado temos a visão de que, ao invés de distanciar, as traduções de obras literárias para mídias de massa aproximam o público da literatura, mesmo que por intermédio de outro meio semiótico. Dentre os argumentos que dão suporte a essa segunda ideia destaca-se o fato de que grande parte do contato com obras literárias, sejam elas impressas ou em outros suportes, se dá por meio de traduções. Esse é o caso, por exemplo, do contato com os clássicos da literatura universal, escritos originalmente em outras línguas, ou com textos produzidos em língua portuguesa há alguns séculos que necessitam de tradução para a linguagem contemporânea para serem compreendidos.

Sobre essa contenda, Nunes (2006) nos diz que a tradução de obras literárias para outros suportes, como a TV e o cinema, por exemplo, pode gerar dois efeitos: tanto o de distanciar o leitor da obra literária original, quanto o de aproximá-lo dela, a depender das intenções e ideologias envolvidas nos processos de tradução e recepção.

Ainda, sobre as diferenças entre obra original e obra midiática traduzida, a autora esclarece que os novos significados e sentidos alcançados pelas traduções da mídia são inerentes às mudanças dos meios de comunicação, tal como aconteceu quando a imprensa foi substituída pelo rádio e o cinema pela TV. Nesses casos, novos meios midiáticos inevitavelmente provocam mudanças nas características dos textos por eles divulgados. A autora ressalta ainda que cada suporte, em seu processo criativo, tem suas próprias regras, e por isso muitas vezes as traduções passam a construir novas obras, que podem ou não reproduzir em sua totalidade os sentidos e ideologias da obra original.

De fato, alterações do texto literário decorrentes de mudanças do suporte em que ele é publicado não é algo característico apenas das mídias audiovisuais. No século XIX, por exemplo, quando romances deixaram os livros e passaram a ser publicados em jornais para atender a novos hábitos de um público ávido pela leitura, a fragmentação do texto e a sucessividade da narrativa nas edições seguintes visavam instigar tanto o 
apetite e curiosidade do leitor quanto o aumento da tiragem dos jornais. Nadaf (2009), ao discutir sobre as primeiras décadas do romance-folhetim no Brasil, deixa claro que a própria constituição do gênero é decorrente da tradução de textos de outras línguas e da transferência de hábitos de outras culturas ao nos dizer que "o folhetim constituiu-se, em sua quase totalidade, de traduções dos clássicos do romance-folhetim, de novelas curtas e do romance tradicional francês" (Nadaf, 2009, p. 123).

Guimarães (1996), sobre o papel da TV na divulgação literária no Brasil a partir da década de 50, nos diz que "jamais existiu entre nós uma literatura popular de alcance nacional" (Guimarães, 1996, p. 192). Segundo o autor, foi a televisão que recentemente passou a satisfazer a necessidade de ficção e poesia de grande parte da população brasileira.

Compartilhando das ideias de Guimarães (1996) e Nunes (2006), neste trabalho buscamos discutir sobre a relação entre texto literário e a TV pela ótica da teoria da tradução (Jakobson, 1959/1999; Nida, 1964; Campos, 1975; Plaza, 1987; Arrojo, 2003; Diniz, 1999; Campos, 2011), que vê a relação entre texto literário impresso e texto audiovisual traduzido como um processo criativo de reconstrução, decorrente da transposição de sentidos de um suporte e cultura a outros.

Para isso, apresentaremos uma revisão da literatura tendo como tema o papel do tradutor como coautor do texto audiovisual traduzido, que em graus variados é obrigado a distanciar-se do texto original impresso para a obtenção da equivalência na obra audiovisual. Inicialmente, discutiremos a Tradução Intersemiótica ou, como definiu Jakobson (1969/1999), transmutação. Em seguida, falaremos sobre os conceitos de equivalência e transcriação, construtos teóricos que priorizam o papel de coautoria do tradutor. Por fim, teceremos algumas conclusões sobre a diferença entre o texto original impresso e o texto traduzido para o meio audiovisual, como a TV e o cinema, mostrando que esta é, na verdade, uma consequência natural da mudança de meio semiótico, da cultura de recepção e das escolhas do tradutor.

\section{Tradução como transmutação}

Jakobson foi quem primeiro propôs o termo tradução intersemiótica, ou transmutação, para descrever as traduções de obras literárias para o cinema ou outros meios. Segundo o autor, ela "consiste na interpretação de signos verbais por meio de signos não verbais" (Jakobson, 1969/1999, p. 65). Plaza reafirma a importância de Jakobson para a definição do termo ao nos dizer que: 
A primeira referência (explícita) à Tradução Intersemiótica que tive oportunidade de conhecer foi nos escritos de Roman Jakobson. De que tenho notícia, Jakobson foi o primeiro a descriminar e definir os tipos possíveis de tradução: a interlingual, a intralingual e a intersemiótica. (Plaza, 1987, p. XI)

Jakobson (1969/1999), ao cunhar o termo transmutação, sinaliza para a impossibilidade da tradução enquanto mecanismo de transferência fiel de todos os significados do texto original para o texto traduzido já que, para ele, transmutar implica em operar uma "mudança" não só nos meios que funcionam como suporte para as obras originais e traduzidas, mas também nas estruturas e nos sentidos do texto de partida de modo a gerar novos textos e novos significados que ainda remetam ao texto original. Para o autor, esse processo de mudança é característico do próprio ato de comunicação, mesmo quando não há línguas ou meios semióticos diferentes envolvidos no processo, tal como ele nos ilustra abaixo:

Para o Linguista como para o usuário comum das palavras, o significado de um signo linguístico não é mais que sua tradução por um outro signo que lhe pode ser substituído, especialmente um signo "no qual ele se ache desenvolvido de modo mais completo", como insistentemente afirmou Peirce, o mais profundo investigador da essência dos signos. O termo "solteiro" pode ser convertido numa designação mais explícita, "homem não-casado", sempre que maior clareza for requerida. (Jakobson, 1969/1999, p. 64)

Assim como Jakobson, Plaza (1987) adota o termo transmutação para as traduções feitas a partir da literatura para outros meios semióticos. Adotando, ainda, o conceito de signo proposto por Charles Sanders Peirce, Plaza defende que o próprio pensamento consiste em um processo de tradução, já que "quando pensamos, traduzimos aquilo que temos presentes à consciência, sejam imagens, sentimentos ou concepções em outras representações que também servem como signos" (Plaza, 1987, p. 18). Ainda para o autor, todo pensamento é tradução de outro pensamento, uma vez que, seja em interações com outros, ou com nós mesmos, organizamos o pensamento de forma dialógica, ou seja, quando pensamos, mantemos um diálogo com um observador leitor interior que é o nosso próprio consciente antes mesmo de qualquer forma de expressão exterior.

Com isso, Plaza (1987) relaciona tradução e linguagem como elementos inseparáveis: utilizar a linguagem seria, antes de tudo, traduzir a nós mesmos. Para ele, o pensamento existe na mente humana como um signo em estado de formulação. Para 
ser plenamente realizado, esse signo precisa ser traduzido pela linguagem. Essa, por sua vez, é um mecanismo de mediação do homem com o real, determinado histórico e culturalmente. De acordo com o autor, a linguagem é um sistema destituído de significados fechados, ou seja, que está sempre aberto às possibilidades interpretativas. Ela é o "principal instrumento da recusa humana em aceitar o mundo como ele é" (Plaza, 1987, p.19) e impossível de ser dissociada da criatividade.

Ainda sobre a linguagem como fenômeno tradutório, Jakobson nos diz que "nenhum espécime linguístico pode ser interpretado pela ciência da linguagem sem uma tradução dos seus signos em outros signos pertencentes ao mesmo ou a outro sistema" (Jakobson, 1969/1999, p. 66).

Como parte inerente da linguagem, e assim como ela, a tradução, para Jakobson e Plaza, é um processo naturalmente criativo. Jakobson (1969/1999), em decorrência dessa concepção, adota o termo equivalência para descrever a transferência de sentidos do texto original para o texto traduzido. Por equivalência em tradução assume-se que a transferência total do sentido e da forma do texto original para o texto traduzido é impossível, devendo o tradutor buscar sentido e forma equivalentes na língua, cultura ou suporte de chegada.

\section{Tradução e equivalência}

Assim como Jakobson, Nida (1964) também adota a obtenção da equivalência como a finalidade do tradutor. Este, entretanto, a divide em duas categorias que refletem o nível de aproximação ou distanciamento que o tradutor deseja obter do texto original: a equivalência formal e a equivalência dinâmica.

$\mathrm{Na}$ equivalência formal o texto traduzido deve se aproximar ao máximo da forma e do sentido do texto original. Nessa abordagem, privilegiam-se os elementos da cultura e da língua de partida. Já na equivalência dinâmica, valorizam-se a cultura e a língua de chegada, de modo que o texto traduzido apresenta maior distanciamento do original em nome da busca pela forma e significados aceitos na cultura e língua de chegada.

Para Jakobson (1969/1999), entretanto, a tradução é apenas uma interpretação adequada de uma unidade do código. A equivalência total, para ele, é impossível de ser alcançada, sendo a transposição criativa a única solução. Ao tratar da tradução poética, por exemplo, o autor nos diz que somente pela criatividade o tradutor pode conciliar forma e conteúdo. 
A poesia, por definição, é intraduzível. Só é possível a transposição criativa: transposição intralingual — de uma forma poética a outra - , transposição interlingual ou, finalmente, transposição inter-semiótica - de um sistema de signos para outro, por exemplo, da arte verbal para a música, a dança, o cinema ou a pintura. (Jakobson, $1969 / 1999$, p.72)

Da mesma forma que para Jakobson, para Plaza (1987) a tradução literária é um processo artístico criativo, uma vez que ela vai além da tradução de características meramente linguísticas e é motivada por fatores históricos e culturais, além da tradição literária e das práticas de linguagem que circundam a obra original e a traduzida. Para o autor, a operação tradutora como trânsito criativo de linguagens nada tem a ver com a fidelidade, pois depende de uma relação fortemente tramada entre seus diversos momentos, ou seja, entre passado, presente, futuro, lugar e tempo nos quais se processam os movimentos de transformação de estruturas e eventos.

\section{Tradução literária como transcriação}

Enquanto Jakobson (1969/1999) e Plaza (1987) advogam em favor da tradução criativa de textos literários como forma de se buscar a equivalência, Augusto e Haroldo de Campos, adotando o lema modernista "make it new" (North, 2013), levam a tradução literária a novos limites. Com sua estética da transcriação, os autores propõem a criatividade do tradutor e a desconstrução do texto original como instrumentos para resgatar os sentidos e valores estéticos do original no texto traduzido. Na transcriação como tradução, o novo texto (traduzido) busca, por meio do aparente distanciamento do original, de fato uma aproximação com o texto de partida, uma vez que seu objetivo é reproduzir em uma outra língua, contexto ou cultura, a essência do original, o que não seria possível se o objetivo fosse a transferência de sentidos e forma em todos os seus aspectos.

Nessa perspectiva, valoriza-se a criatividade tradutória como forma de aproximar original e texto traduzido. Sobre isso, Diniz (1999) nos diz que essa criatividade consiste na busca por sistemas equivalentes que permitem ao leitor reconhecer a obra original. Isso pode ser observado na figura abaixo, que traz um dos poemas traduzidos por Augusto de Campos (1975) a partir da obra de William Blake: 

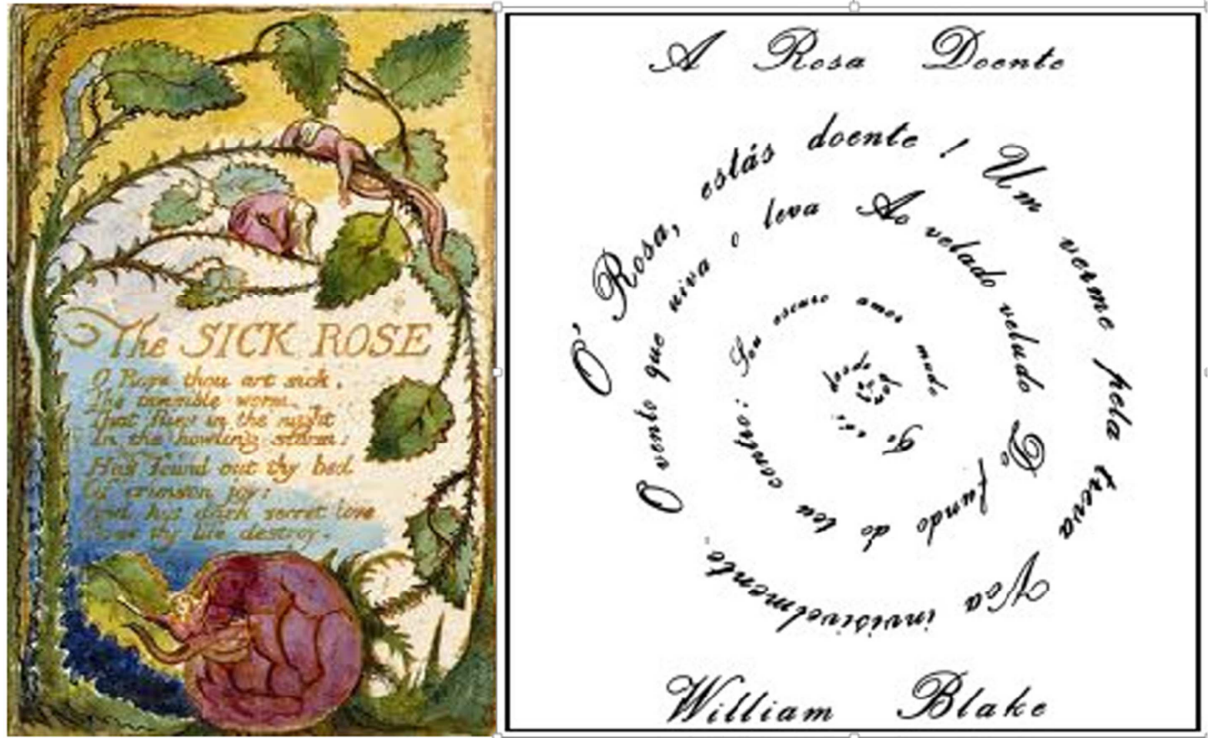

FIGURA 1: Transcriação do poema “The Sick Rose", de William Blake, por Augusto de Campos ${ }^{1}$

No exemplo anterior, o aparente distanciamento entre original e tradução carrega, na verdade, estratégias que visam a aproximação entre elas, tal como o formato circular do texto traduzido, que faz referência ao formato da rosa; o tamanho das letras, que ao diminuírem gradualmente da periferia para o centro da imagem evocam o verme que corrói a flor; e a presença do nome do autor do texto original no fim do poema, que visa exaltar a autoria do texto original.

De forma semelhante, podemos perceber a relação entre criatividade do tradutor e fidelidade ao texto original em uma outra tradução do mesmo poema de William Blake, divulgada em suporte audiovisual. De autoria anônima, a obra publicada no canal de vídeos on-line YouTube busca aproximação com o texto original ao exibir na tela o poema escrito por Blake em inglês. Na tradução, o texto escrito, assim como na obra original, aparece associado a imagens que sugerem visualmente uma interpretação de cunho sexual e dramático. No texto original a gravura revela uma figura feminina que é a própria rosa, corroída pelo verme. No vídeo, a rosa também é associada à imagem de uma mulher, cujas formas aparecem de relance, sendo acariciadas por uma mão masculina, que assume o lugar do verme. Diferentemente do original, as cores predominantes no vídeo são o preto, o branco e o vermelho, que buscam resgatar versos do poema como "The invisible worm" e "And his dark secret love". Da mesma forma, a música que toca ao fundo, ausente na obra original, busca uma aproximação da tradução

\footnotetext{
${ }^{1}$ Fonte: https://flabbergasted2.wordpress.com/tag/augusto-de-campos
} 
com o texto de partida. $\mathrm{O}$ som de violoncelo que acelera à medida que o vídeo é exibido evoca tanto o movimento e a dramaticidade do verme que corrói a rosa quanto os versos do poema "The howling storm" e "Of crimson joy", já que o tom grave e rítmico do instrumento musical remete tanto o som de uma tempestade quanto à ideia do clímax sexual.

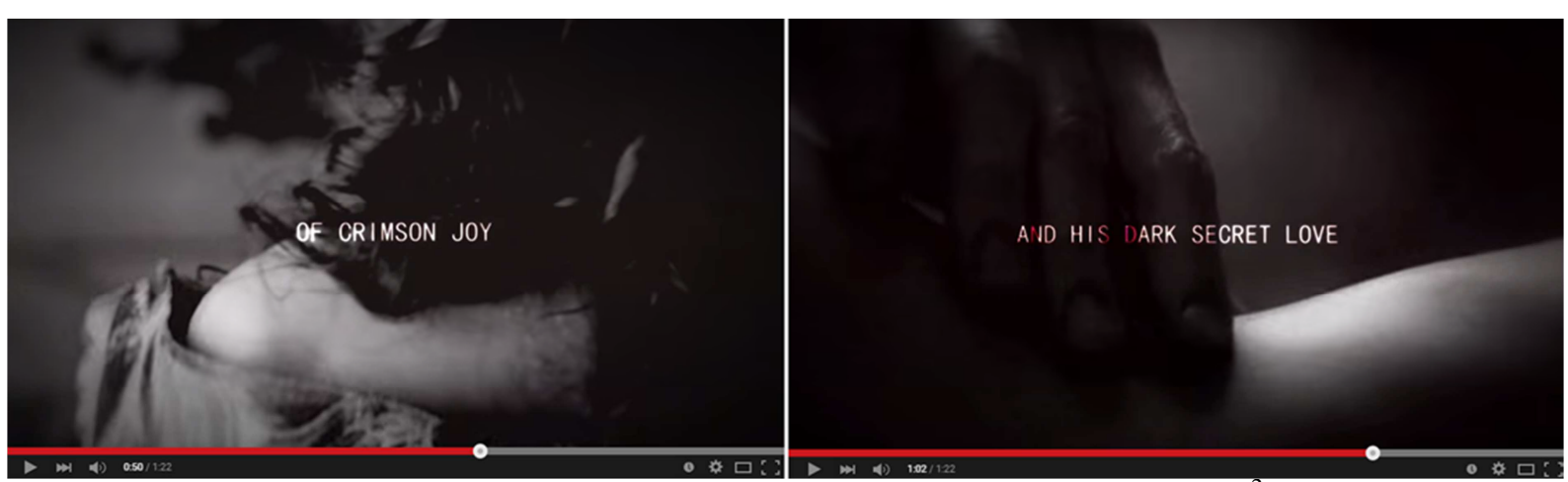

FIGURA 2: Tradução audiovisual do poema The Sick Rose publicada no Youtube ${ }^{2}$

Para Diniz (1999), cada atividade semiótica organiza-se de maneira distinta em seu próprio sistema de sentido. O vídeo, por exemplo, embora frequentemente parta do texto literário, desenvolveu seu próprio método de narrar como fruto das características do meio audiovisual, que envolve recursos e problemas diferentes do literário escrito. Assim, mesmo que se buscasse total fidelidade, a tradução audiovisual, do mesmo modo que qualquer tradução de um sistema de signos para o outro, inevitavelmente traria semelhanças e diferenças.

Para a autora a tradução de uma obra literária envolve, obrigatoriamente, os processos de leitura, interpretação e produção de textos por parte do tradutor, o que leva a diferenças entre original e tradução, independente do suporte em que estão publicados. Em suas palavras:

Tradicionalmente, define-se tradução como o ato de transportar, transferir, supondo-se a existência de algo inerente ao texto, um sentido, que vai ser transportado. As modernas teorias de leitura, entretanto, defendem que um texto só existe à medida em que é lido, o que descarta a possibilidade de um texto pronto, cheio de significados que serão "descobertos" e, em seguida, transferidos. Traduzir envolve um processo mais abrangente do que a via unidirecional. O texto resultante, a tradução, não consiste da incorporação do texto anterior "transportado", e sim de um texto que se refere a outro(s) texto(s), que o(s) afeta, que mantém com ele(s) uma determinada relação ou que ainda o(s) representa de algum modo. É esse modo pelo qual um representa outro(s), é esse

\footnotetext{
${ }^{2}$ Fonte: https://www.youtube.com/watch?v=8VqTwIeqkf8
} 
tipo de relação que existe entre eles que é o objeto dos estudos de tradução intersemiótica. (Diniz, 1999. p. 313)

Arrojo (2003) também compartilha a visão de criação como instrumento no processo tradutório. Para a autora, o processo de tradução passa, antes de tudo, pela leitura e interpretação do texto pelo tradutor, tal como podemos verificar no trecho abaixo:

\begin{abstract}
Ainda que um tradutor conseguisse chegar a uma repetição total do texto, sua tradução não recuperaria nunca a totalidade do original; ela revelaria, inevitavelmente, uma leitura, uma interpretação desse texto que, por sua vez, será, sempre, apenas lido e interpretado, e nunca totalmente decifrado ou controlado (Arrojo, 2003. p. 22).
\end{abstract}

Desse ponto de vista, a tradução de uma obra literária para o meio audiovisual revelaria, inevitavelmente, a interpretação dos roteiristas, produtores e diretores da obra audiovisual e as tentativas de reconstrução desse texto com base em suas interpretações.

Nida (1964), ao descrever o processo da tradução, em que o tradutor, inicialmente o receptor da mensagem original, realiza operações de transformação da mensagem para tornar-se emissor da mensagem traduzida, nos apresenta um modelo no qual o tradutor é mais do que simplesmente responsável por transportar significados; ele é visto como coautor do texto traduzido. A seguir, apresentamos uma versão simplificada do modelo, publicada por Nida e Taber (1969, p. 33):

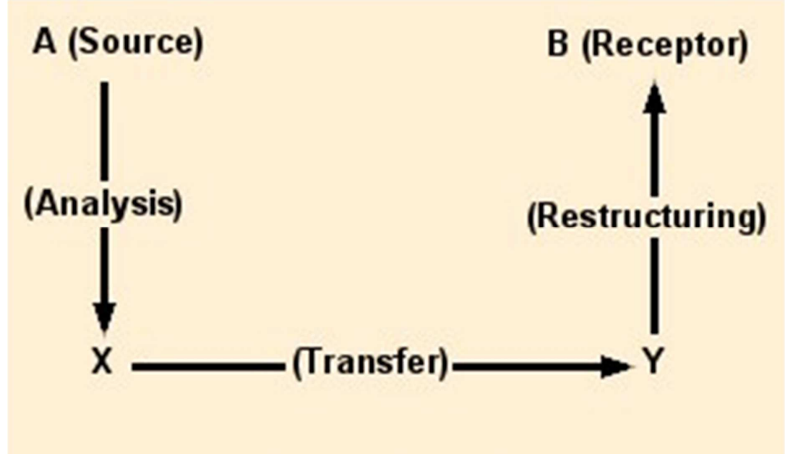

FIGURA 3: O processo de Tradução (Nida \&Taber, 1969, p. 33)

Na tradução de obras literárias para a TV e o cinema, as diferenças entre o texto original e o traduzido são facilmente percebidas por espectadores que tiveram acesso às duas obras. Entretanto, tais diferenças refletem que o processo de tradução não se 
resume somente à transferência de sentido de uma obra à outra. Dentre os fatores que precisam ser considerados por quem os traduz estão os culturais, os sociais, os ideológicos, os históricos, os econômicos, dentre outros. Não podemos esquecer que tanto livros quanto filmes, novelas ou outras produções audiovisuais são geralmente feitas para agradar a públicos específicos e que geralmente visam vender um produto ou ideologia. Os mesmos princípios de produção se aplicam ao processo de tradução. Livros produzidos para uma determinada cultura, quando traduzidos para a TV e o cinema, por exemplo, podem não ser bem recebidos se não houver uma busca por aspectos culturais equivalentes no contexto de recepção.

Um exemplo disso é o filme franco-suíço-brasileiro Abril Despeçado (2001), dirigido por Walter Salles e traduzido da obra literária albanesa de Ismail Kadaré (1978/2001). Em seu contexto original, o livro de Kadaré é ambientado nas montanhas do norte da Albânia e gira em torno do código de leis adotado pelos habitantes daquela região, que estabelece regras para as disputas familiares, dentre outras situações. No livro, membros de famílias rivais são obrigados a vingar a morte de parentes que foram vítimas do conflito entre elas por meio do assassinato de um membro da outra família, em um ciclo que dura por gerações. Na tradução de Walter Salles, a premissa da vingança e da obrigação familiar foi transportada para o Nordeste brasileiro do início do século $\mathrm{XX}$, quando a ausência do Estado deixava espaço para que conflitos fossem resolvidos de forma brutal.

Sobre o filme, Boscov (2002), em reportagem para a Veja On-line, traz à tona a discussão sobre o status da tradução em relação ao original ao tecer os seguintes comentários:

O diretor Walter Salles tem grande admiração pelo albanês Ismail Kadaré, de quem adaptou o livro Abril Despedaçado para o cinema. O escritor, por sua vez, desmanchouse em elogios ao brasileiro ao ver o filme, que considera a melhor adaptação de sua obra até aqui. Entre os dois, tem mais razão Kadaré. Abril Despedaçado (Brasil/Suíça/França, 2001), que estreia nesta quarta-feira no país, é um dos poucos casos de versões cinematográficas que avançam sobre o original literário e saem mais coesas, coerentes e talentosas do que ele. (Boscov, 2002)

Abaixo, podemos ver, à esquerda, capas de algumas das edições da obra de Kadaré traduzidas para outras línguas. À direita, temos cenas e cartazes da tradução cinematográfica ambientada no Nordeste do Brasil, ilustrando o alcance da obra audiovisual na divulgação do texto original impresso. Assim como em Abril 
Despedaçado, inúmeras outras traduções de obras literárias optam por buscar na diferença a equivalência com os textos originais.

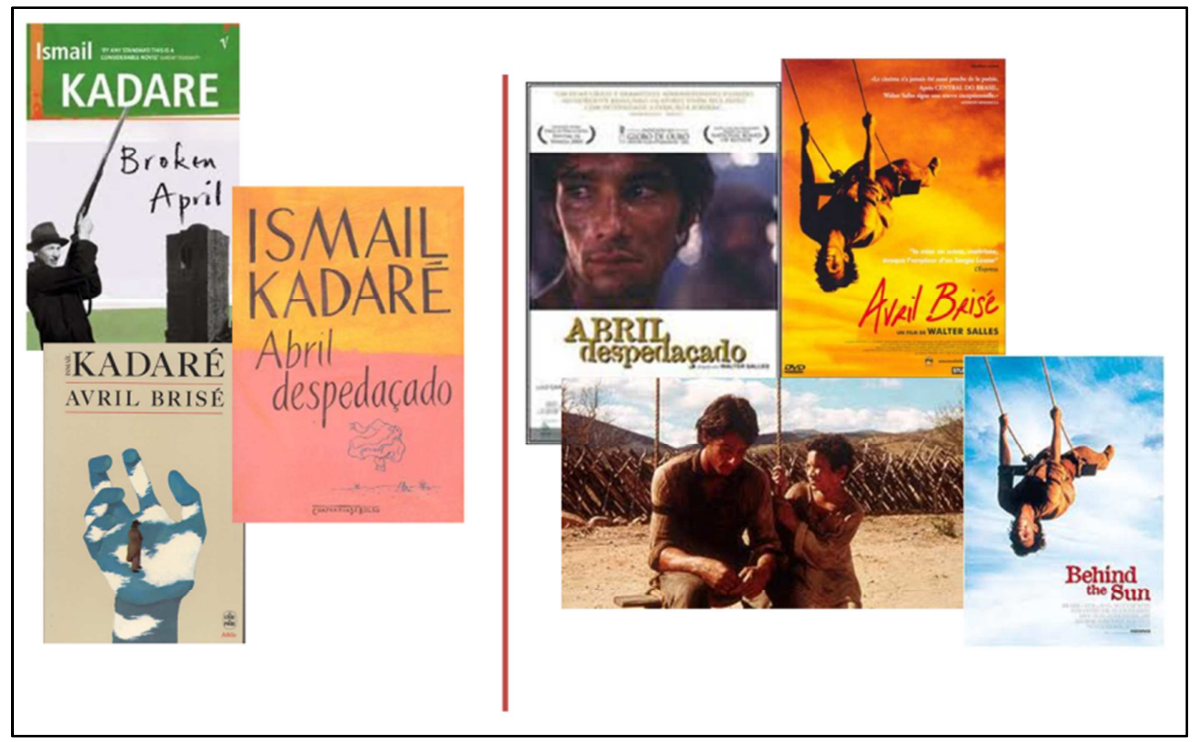

FIGURA 4: Traduções da obra literária Abril Despedaçado para o cinema

\section{Considerações Finais}

Ao contrário do que muitos pensam, as teorias de tradução contemporâneas não são normativas, não cabendo a elas instruir os tradutores quanto à melhor tradução. Elas são, na verdade, pragmáticas. A partir delas, o tradutor decide-se por aquelas, dentre as soluções possíveis, que parecem ter o máximo de efeito com um mínimo de esforço, avaliando perdas e ganhos.

$\mathrm{Na}$ tradução de obras literárias impressas para o meio audiovisual o tradutor deve lançar mão dos recursos inerentes à linguagem da imagem em movimento. Enquanto no texto verbal características de personagens, de lugares e o desenrolar de eventos ficam em grande parte sob a responsabilidade do leitor, com base nas pistas dadas pelo autor do texto, nas traduções para o cinema e para a TV as imagens já estão lá. Nesse caso, elas refletem, antes de tudo, as interpretações e escolhas dos tradutores, sejam eles o roteirista, o diretor, o produtor, dentre outros.

Além dessas, inúmeras outras diferenças entre os dois meios semióticos implicam que o processo de tradução, inevitavelmente, levará a mudanças do texto original. Na linguagem televisiva e cinematográfica, por exemplo, a emoção pode ser o resultado obtido pelo jogo de câmeras, pela montagem, pela trilha sonora, pela 
iluminação e fotografia, dentre outros elementos que compõem as narrativas audiovisuais, o que deixa claro o papel de coautor do tradutor na obra traduzida.

\section{Referências}

ARROJO, R. Oficina de tradução: a teoria na prática. São Paulo: Ática, 2003.

ABRIL Despedaçado. Direção: Walter Salles. Lumiere. 2001. DVD. 105 min.

BOSCOV, I. Melhor que o livro. Veja on-line. Edição 1749. 01 de maio 2002.

Disponível em: http://veja.abril.com.br/110401/p_148.html Acesso em 20.04.13.

CAMPOS, A. Pontos - Periferia - Poesia Concreta. In: CAMPOS, H.; CAMPOS, A.; PIGNAtaRi, D. Teoria da Poesia Concreta - textos críticos e manifestos 1950 -1960. 2. ed. São Paulo: Duas Cidades, 1975. p.17-25.

CAMPOS, H. Da transcriação poética e semiótica, da operação tradutora. Belo Horizonte: FALE/UFMG, 2011.

DINIZ, T. F. N. Tradução Intersemiótica: do texto para a tela. Cadernos de Tradução, v. 3, p. 313-338, 1999.

GUIMARÃES, H. A presença da literatura na televisão. Revista USP, n. 32, p. 190 198, 1996.

KADARÉ, I. Abril despedaçado. Tradução de Benardo Joffily. São Paulo: Companhia das Letras, 2001.

JAKOBSON, R. Linguística e comunicação. São Paulo: Cultrix, 1999.

NADAF, Y. J. O romance-folhetim francês no Brasil: um percurso histórico. Letras, Santa Maria, v. 19, n. 2, p. 119-138, jul./dez. 2009.

NIDA, E. A. Toward a Science of Translating. Leiden: Brill. 1964.

NIDA, E.; TABER, C.R. The Theory and Practice of Translation. Leiden: E.J. Brill, 1969.

NORTH, M. Novelty: A History of the New. Chicago: University of Chicago Press. 2013.

NUNES, A. M. O. A Literatura na TV. UNESCOM - Congresso Multidisciplinar de Comunicação para o Desenvolvimento Regional. São Bernardo do Campo: Universidade Metodista de São Paulo. 2006.

PLAZA, J. Tradução Intersemiótica. São Paulo: Perspectiva, 1987. 